\title{
Epidermal growth factor expression as a predictor of chemotherapeutic resistance in muscle-invasive bladder cancer
}

\author{
Ahmed M. Mansour ${ }^{1,2}$, Mona Abdelrahim ${ }^{1}$, Mahmoud Laymon ${ }^{1}$, Mamdouh Elsherbeeny ${ }^{1}$, Mohammed Sultan ${ }^{1}$, \\ Ahmed Shokeir ${ }^{1}$, Ahmed Mosbah¹, Hassan Abol-Enein ${ }^{1}$, Amira Awadalla', Eunho Cho ${ }^{3}$, Vikram Sairam³, \\ Taeeun D. Park', Muhammad Shahid ${ }^{5}$ and Jayoung $\mathrm{Kim}^{3,5^{*}}$
}

\begin{abstract}
Background: Epidermal growth factor receptor (EGFR) overexpression is believed to be associated with bladder cancer (BC) progression and poor clinical outcomes. In vivo studies have linked EGFR subcellular trafficking and chemo-resistance to cisplatin-based chemotherapies. This has not been studied in the clinical adjuvant setting. We aimed to investigate the prognostic significance of EGFR expression in patients receiving cisplatin-based adjuvant chemotherapy following radical cystectomy for advanced BC.

Methods: The database from the Urology and Nephrology Center at Mansoura University was reviewed. BC patients who were treated with radical cystectomy and adjuvant chemotherapy for adverse pathological features or node positive disease were identified. Patients who underwent palliative cystectomy, had histological diagnoses other than pure urothelial carcinoma, or received adjuvant radiotherapy were excluded from the study. Immunohistochemical staining for EGFR expression was performed on archived bladder specimens. The following in vitro functional analyses were performed to study the relationship of EGFR expression and chemoresponse.

Results: The study included 58 patients, among which the mean age was 57 years old. Majority of patients had node positive disease $(n=53,91 \%)$. Mean follow up was 26.61 months. EGFR was overexpressed in 25 cystectomy specimens (43\%). Kaplan-Meier analysis revealed that EGFR over-expression significantly correlated with disease recurrence $(p=0.021)$. Cox proportional hazard modeling identified EGFR overexpression as an independent predictor for disease recurrence $(p=0.04)$. Furthermore, in vitro experiments demonstrated that inhibition of EGFR may sensitize cellular responses to cisplatin.

Conclusions: Our findings suggest that EGFR overexpression is associated with disease recurrence following adjuvant chemotherapy for advanced BC. This may aid in patient prognostication and selection prior to chemotherapeutic treatment for BC.
\end{abstract}

Keywords: EGFR, Bladder cancer, Survival, Adjuvant chemotherapy

\footnotetext{
* Correspondence: Jayoung.kim@csmc.edu

${ }^{3}$ University of California Los Angeles, Los Angeles, CA, USA

${ }^{5}$ Departments of Surgery and Biomedical Sciences, Samuel Oschin

Comprehensive Cancer Institute, Cedars Sinai Medical Center, 8700 Beverly

Blvd, Los Angeles, CA 90048, USA

Full list of author information is available at the end of the article
}

(c) The Author(s). 2018 Open Access This article is distributed under the terms of the Creative Commons Attribution 4.0 International License (http://creativecommons.org/licenses/by/4.0/), which permits unrestricted use, distribution, and reproduction in any medium, provided you give appropriate credit to the original author(s) and the source, provide a link to the Creative Commons license, and indicate if changes were made. The Creative Commons Public Domain Dedication waiver (http://creativecommons.org/publicdomain/zero/1.0/) applies to the data made available in this article, unless otherwise stated. 


\section{Background}

Bladder cancer (BC) is the second most common genitourinary malignancy and the fourth most common cancer in the United States (U.S.). Over an estimated \$4 billion/ year is spent on BC treatment annually in the U.S., making $\mathrm{BC}$ one of the most expensive cancer treatments to date [1-3]. Currently, $\mathrm{BC}$ is also the most common cancer in Egyptian males, representing about $30 \%$ of all cancer types [4]. Thus, BC is a major burden on the health services and economic resources at an international level [5]. Despite the drastic decrease in the prevalence of schistosomiasis in Egypt due to nationwide anti-bilharzial campaigns, there has been an increase in incidences of bladder urothelial carcinoma. This could possibly be due to smoking and carcinogenic chemical exposure $[6,7]$.

The gold standard therapy for patients with muscle-invasive bladder cancer (MIBC) is radical cystectomy with regional lymphadenectomy. Despite local aggressive therapy, nearly half of patients eventually develop metastasized tumors and, ultimately, die from the disease [8]. In an attempt to improve survival, integration of systemic chemotherapy with surgical management has been suggested to control micrometastasis [9]. However, around $40 \%$ of patients receiving neoadjuvant chemotherapy are termed "non-responders", with a complete pathological down-staging rate of only $14-38 \%[10,11]$. MIBC patients who do not respond to adjuvant chemotherapy generally have a poor prognosis [12]. The incidence of $\mathrm{BC}$ recurrence following chemotherapy remains high with a modest survival advantage of $5-15 \%$. Thus, there is an important and urgent need to identify prognostic marker(s) that will identify patients who are at risk and to better understand the functional contribution of potential predictive markers in aggressive BC.

Prior research has shown that epidermal growth factor receptor (EGFR) overexpression has been associated with $\mathrm{BC}$ progression and poor clinical outcomes [13, 14]. In vivo studies have linked EGFR subcellular trafficking and chemo-resistance in many tumor types $[15,16]$. However, this has not yet been studied in the clinical adjuvant setting.

In this study, we aimed to investigate the prognostic significance of EGFR expression in patients receiving adjuvant chemotherapy. Our study was conducted on an Egyptian cohort. Our findings suggest that EGFR protein expression may be indicative of aggressive $\mathrm{BC}$ and these expression patterns possibly involve direct action on signaling pathways in $\mathrm{BC}$ cells.

\section{Methods}

\section{Patients and tissue samples}

All of the enrolled patients had been treated with similar or identical regimens with at least four cycles of cisplatin-based chemotherapy. Patients previously treated with radical cystectomy and had completed adjuvant chemotherapy for adverse pathological features or node positive diseases were selected. Exclusion criteria were applied to patients who underwent palliative cystectomy, those with histological diagnosis other than pure transitional cell carcinoma, and patients who received adjuvant radiotherapy. Bladder tumors were staged according to the 2002 TNM classification. Disease progression was defined as newly diagnosed distant metastases with $a \geq 20 \%$ increment increase in tumor mass following radical cystectomy. Surgical tumor tissues were macro-dissected, typically within $15 \mathrm{~min}$ of surgical resection. Each BC specimen was confirmed as representative by analysis of adjacent tissue in fresh frozen sections from radical cystectomy specimens.

\section{Reagents}

Cisplatin was purchased from Sigma. Antibodies against EGFR and $\beta$-actin were obtained from Cell Signaling Technology (for Western blot analysis), Abcam (for IHC analysis) and Santa Cruz Biotechnology. The ECL detection kit was from BioRad and New England Nuclear. All other biochemical reagents were purchased from Sigma or BD Biosciences.

\section{Immunohistochemical staining}

Immunohistochemical (IHC) analysis for EGFR expression was performed on archived bladder specimens. The relationship of EGFR expression and clinical outcomes was assessed. In vitro studies were performed to determine whether EGFR expression was associated with resistance to chemotherapeutic reagents. Paraffin blocks from 58 BC cases were used for immunohistochemical analysis. Tissue sections were cut and placed on Superfrost Plus microscope slides. Using the Benchmark XT automated immunohistochemistry stainer (Ventana Medical Systems, Inc., Tucson, AZ, USA), slides were stained following typical procedure. Detection was done using the Ventana Ultraview DAB Kit (Ventana Medical Systems).

Sections were deparaffinized using EZ Prep solution. CC1 standard ( $\mathrm{pH} 8.4$ buffer contained Tris/Borate/ EDTA) was used for antigen retrieval. DAB inhibitor (3\% $\mathrm{H}_{2} \mathrm{O}_{2}$, Endogenous peroxidase) was blocked for $4 \mathrm{~min}$ at $37{ }^{\circ} \mathrm{C}$ temperature. Sections were incubated with an anti-EGFR (Cat \# ab32077, Abcam Inc., San Diego, CA, dilution 1/100) primary antibody for $40 \mathrm{~min}$ at $37{ }^{\circ} \mathrm{C}$, and then incubated with a secondary antibody of Universal HRP Multimer for $8 \mathrm{~min}$ at $37^{\circ} \mathrm{C}$. Slides were then incubated with $\mathrm{DAB}+\mathrm{H}_{2} \mathrm{O}_{2}$ substrate for $8 \mathrm{~min}$, followed by hematoxylin and bluing reagent counterstain at $37{ }^{\circ} \mathrm{C}$. Reaction buffer (pH 7.6 Tris buffer) was used as the washing solution. Staining intensity and proportion of positively-stained cells were evaluated. Staining intensity 
Table 1 Baseline characteristics of the patients in this study

\begin{tabular}{|c|c|c|}
\hline Variables & & Incidence (SD or \%) \\
\hline Age mean (SD) & & $57(6.6)$ \\
\hline \multirow[t]{2}{*}{ No. gender (\%) } & Male & 53(91.4) \\
\hline & Female & $5(8.6)$ \\
\hline \multirow[t]{4}{*}{ No. clinical T stage (\%) } & $\mathrm{T} 2$ & $7(12.1)$ \\
\hline & T3 & $30(51.7)$ \\
\hline & $\mathrm{T} 4 \mathrm{a}$ & $18(31.1)$ \\
\hline & $\mathrm{T} 4 \mathrm{~b}$ & $3(5.2)$ \\
\hline \multirow[t]{7}{*}{ No. pathologic T stage (\%) } & TIS & $1(1.7)$ \\
\hline & $\mathrm{T} 1$ & $1(1.7)$ \\
\hline & $\mathrm{T} 2 \mathrm{a}$ & $7(12.1)$ \\
\hline & $\mathrm{T} 2 \mathrm{~b}$ & $7(12.1)$ \\
\hline & T3a & $22(37.9)$ \\
\hline & T3b & $15(25.9)$ \\
\hline & $\mathrm{T} 4 \mathrm{a}$ & $5(8.6)$ \\
\hline \multirow[t]{4}{*}{ No. pathologic N status (\%) } & No & $5(8.6)$ \\
\hline & N1 & $14(24.1)$ \\
\hline & N2 & $37(63.8)$ \\
\hline & N3 & $2(3.4)$ \\
\hline \multirow[t]{2}{*}{ No. lymphovascular invasion (\%) } & Yes & $45(77)$ \\
\hline & No & $13(23)$ \\
\hline \multirow[t]{2}{*}{ No. strong EGFR expression (\%) } & Yes & $10(17.2)$ \\
\hline & No & $48(82.8)$ \\
\hline
\end{tabular}

was classified as follows: none (score 0 ), weak (score 1), moderate (score 2) and strong (score 3). Each specimen was examined and scored separately by two pathologists, and discrepancies were discussed until agreements were reached.

\section{Cell culture and transfection}

TCCSUP or T24 human BC cells were purchased from American Type Culture Collection (ATCC, Manassas, VA) and maintained in DMEM or RPMI1640 (Invitrogen, Carlsbad, CA) with 10\% FBS and 1\% Penicillin/Streptomycin at $37{ }^{\circ} \mathrm{C}$ under $5 \% \mathrm{CO}_{2}$. The day before transfection, TCCSUP or T24 cells were trypsinized and counted. Cells were plated in 6-well plate with approximately $6.25 \times 10^{5}$ cells per well in $2 \mathrm{ml}$ of complete growth medium. When cell density reached $80-90 \%$ confluence, TCCSUP or T24 BC cells were transiently transfected with 25-50 $\mathrm{nM}$ of small interfering RNAs (siRNAs) targeting EGFR (SignalSilence ${ }^{\bullet}$ EGF Receptor siRNA, Cell Signaling \#6482) using Lipofactamine 2000. For transfection controls, empty (Ctrl) or non-target siRNAs (siCtrl) were used.

\section{Cell viability assay}

Experiments were performed in 6-well plates after cell density reached to about $90 \%\left(2 \times 10^{3} /\right.$ well $)$. TCCSUP or T24 cells were transfected with various constructs or siRNAs and cisplatin simultaneously for $48 \mathrm{~h}$ (siRNA added $2 \mathrm{~h}$ before cisplatin). Cells were then incubated with cisplatin containing serum-free medium (RPMI1640

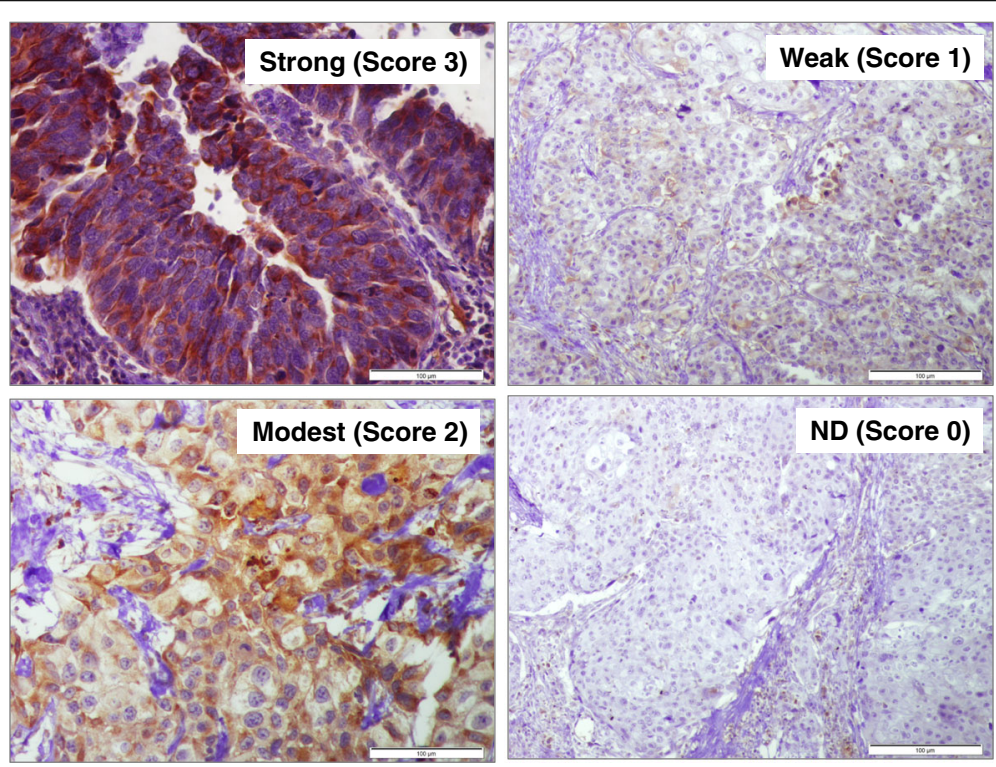

Fig. 1 Representative figures showing IHC slides with different scores. Immunohistochemical staining for EGFR in BC tissue samples. Four representative fields are shown after IHC staining with anti-EGFR (1:1000 dilution). Negative (Score 0), weak (Score 1), intermediate (Score 2), and strong (Score 3). EGFR expression was observed in the cytoplasm, membrane, and/or nucleus in our BC specimens. The intensity of EGFR staining was often heterogeneous within the same cancer tissue. 
Table 2 Cox proportional hazard model of overall survival predictors

\begin{tabular}{|c|c|c|c|c|}
\hline \multirow[t]{2}{*}{ Covariate } & \multicolumn{2}{|l|}{ Univariate } & \multicolumn{2}{|l|}{ Multivariate } \\
\hline & HR $(95 \% \mathrm{Cl})$ & $P$ value & HR $(95 \%$ Cl) & $P$ value \\
\hline Age & $1.41(1.02-2.45)$ & 0.029 & $1.34(0.94-1.77)$ & 0.056 \\
\hline Sex (M vs F) & $1.88(1.06-3.34)$ & 0.048 & $1.48(0.26-1.80)$ & 0.479 \\
\hline $\begin{array}{l}\text { EGFR expression } \\
\text { (strong vs negative/weak/moderate) }\end{array}$ & $1.55(1.30 .-2.33)$ & 0.002 & $1.38(1.201-2.744)$ & 0.004 \\
\hline $\begin{array}{l}\text { Chemotherapy Regimen } \\
\text { (MVAC vs GemCis) }\end{array}$ & $1.72(0.84-3.75)$ & 0.159 & & \\
\hline $\begin{array}{l}\text { PT stage } \\
\text { (T2 or less vs greater than T2) }\end{array}$ & $2.88(1.92-3.99)$ & 0.003 & $3.28(1.54-4.62)$ & $<0.001$ \\
\hline $\begin{array}{l}\text { pN stage } \\
\text { (NO vs greater than N0) }\end{array}$ & $2.31(1.88-2.93)$ & $<0.001$ & $1.81(1.23-2.74)$ & $<0.001$ \\
\hline
\end{tabular}

or DMEM) for the indicated time. Cell viability was determined using MTS reagents, as instructed by the company's protocol (Promega Corporation, Madison, WI).

\section{Statistical analysis}

Univariate analysis with the Pearson chi-square was performed to analyze associations between strong EGFR expression and pT stage, $\mathrm{pN}$ stage, (N0 and greater than N0) and lymphovascular invasion. A Kaplan-Meier estimator curve with the log rank test and a Cox proportional hazard model were used to test whether observed response to chemotherapy predicted disease specific survival.

\section{Results}

Baseline characteristics

The study included 58 patients. The mean age of the 57 patients who received adjuvant therapy was $57 \pm$ 6.6 years, and the mean follow-up period was 26.61 months. A majority of patients had node positive disease $(n=53,91 \%)$. Forty-five patients $(77 \%)$ had lymphovascular invasion. Other baseline characteristics of the patients are presented in Table 1.

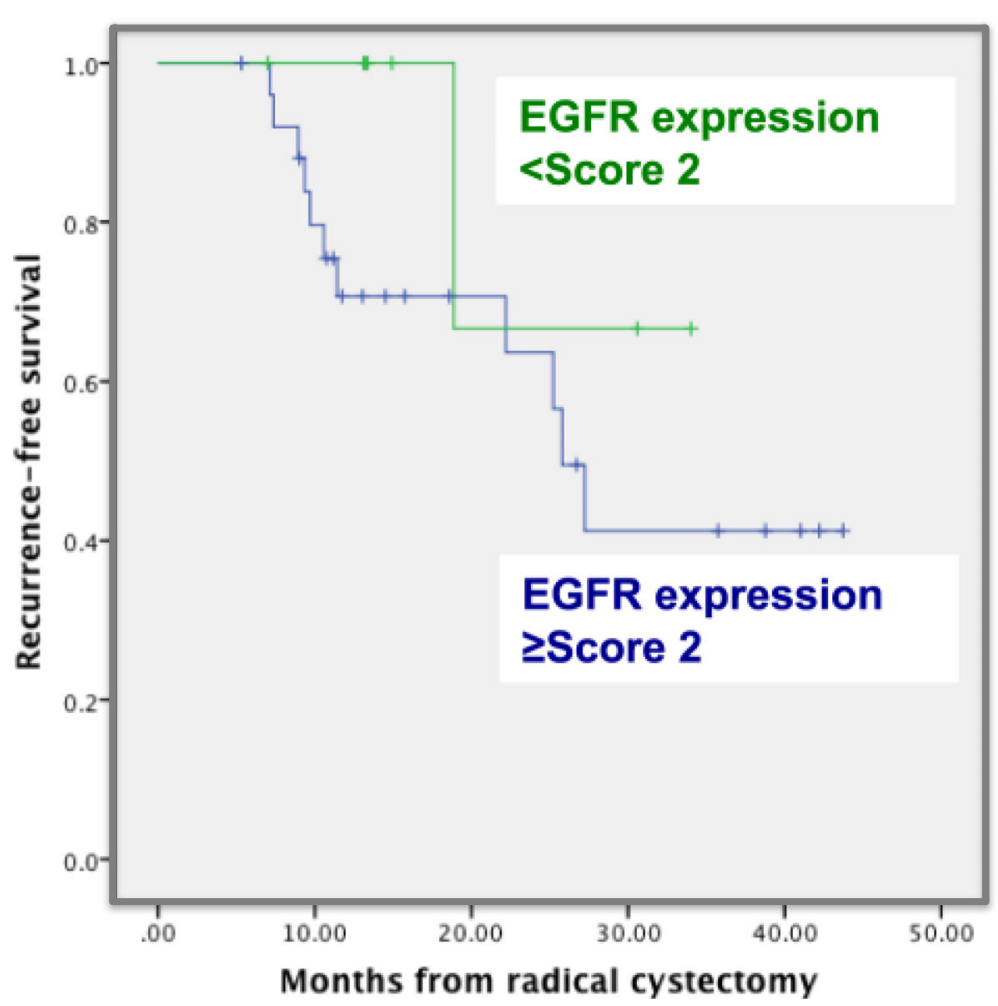

Fig. 2 Cancer-specific survival in BC patients stratified by EGFR staining 

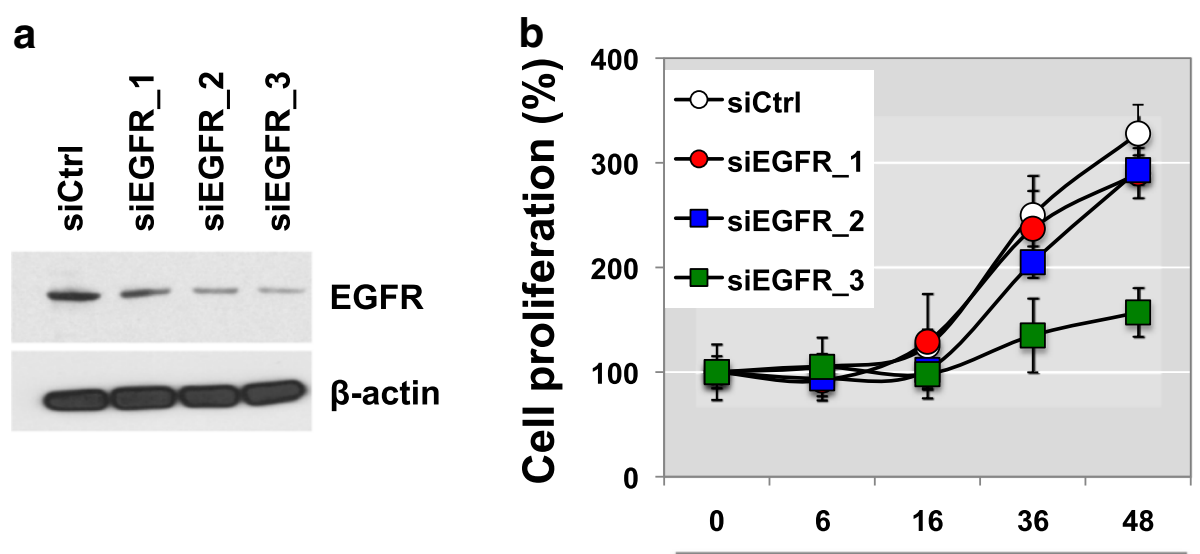

Time (h)

Fig. 3 EGFR expression is associated with drug sensitivity to cisplatin treatment. $\mathbf{a}$, b TCCSUP cells were transiently transfected with varying doses of siRNA against EGFR. Knockdown of EGFR with control and EGFR-targeted siRNAs shows that proliferation in TCCSUP BC cells decreases in a dose-dependent manner (siEGFR_1, siEGFR_2, siEGFR_3). Cell proliferation assay was performed at the indicated time points $(0,6,16,36$, or $48 \mathrm{~h}$ after transient transfection with siRNAs) using MTT assay at the varying time points. ${ }^{*} p<0.05$ (Student's t-test)

EGFR expression is negatively correlated with survival To measure EGFR expression in our cohort, IHC analysis was performed. IHC images were scored from 0 (negative staining) to 3 (highest staining intensity). Representative images are shown in Fig. 1. Cox proportional hazard modeling identified EGFR overexpression as an independent predictor for disease recurrence (OR, $1.38(1.201-2.744), p=0.004)$ in the Egyptian cohort (Table 2). Kaplan-Meier analysis revealed that EGFR overexpression (score $\geq 2$ ) significantly correlated with disease recurrence $(p=$ 0.021) (Fig. 2).

\section{EGFR silencing alters cell proliferation, viability and} response to cisplatin-induced apoptosis

We further performed loss-of-function studies on TCCSUP human BC cells to assess the biological role of EGFR. EGFR was knocked-down using iRNAs and this was subsequently confirmed via western blot analysis (Fig. 3a). Silencing of EGFR did not induce a a

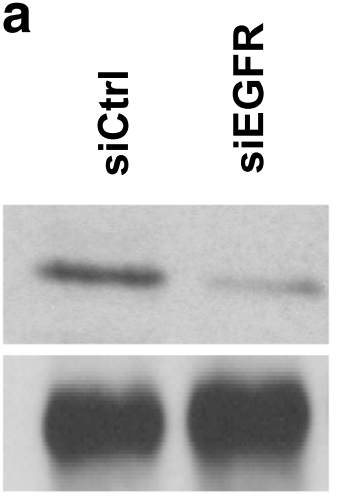

EGFR

$\beta$-actin

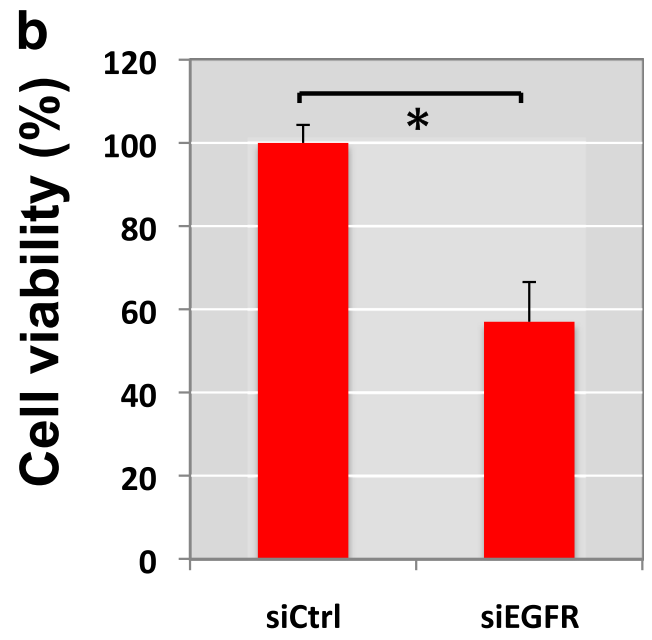

Fig. 4 Knockdown of EGFR suppresses recovery from cisplatin treatment. a EGFR silenced TCCSUP cells (siEFGR) or control TCCSUP cells (siCtrl) were challenged with cisplatin treatment. TCCSUP cells were incubated with cisplatin $(10 \mu \mathrm{M})$ and siRNAs for $48 \mathrm{~h}$ and then re-treated with cisplatin alone for an additional $6 \mathrm{~h}$. After, the cisplatin was removed from the culture media and cells were incubated in normal growth medium for 24 h. b Cell viability was measured using MTT assay. Cell viability levels of three wells of transfected cells were determined. The graph was plotted as \%, compared to control, no cisplatin treatment in siCtrl group $( \pm \mathrm{SD}) .{ }^{*} P<0.05$ (Student's t-test). All experiments were done in at least triplicates 
morphological switch. However, in vitro functional analysis demonstrated that EGFR expression levels can alter cell proliferation rates in TCCSUP BC cells. A dose dependent transfection of EGFR siRNAs (siEGFR_1,_2, or _3) revealed that EGFR deficiency evoked an approximately $50 \%$ decrease in cell proliferation (Fig. 3b). This data implicates that EGFR loss as an important mechanism through which $\mathrm{BC}$ cells keep proliferating.

We next assessed whether loss of EGFR expression can result in cell viability responses in relation to the effects of cisplatin and whether inhibition of EGFR can enhance the sensitivity of $\mathrm{BC}$ cells to cisplatin. We found that EGFR expression is associated with resistance to cisplatin-induced cytotoxicity. EGFR knockdown delayed cell recovery from $10 \mu \mathrm{M}$ cisplatin treatment (Fig. 4).

Viability of control cells (siCtrl) in serum-free medium was compared with or without a challenge by $10 \mu \mathrm{M}$ cisplatin. Cell viability assay revealed that silencing of
EGFR sensitized TCCSUP BC cells to cisplatin treatment. Knockdown of EGFR was validated by western blot analysis (Fig. 4a). Cells transfected with EGFR siRNAs showed around $50 \%$ viability after cisplatin treatment compared to control TCCSUP cells (siEGFR). Removal of cisplatin from the culture medium of control cells resulted in $100 \%$ recovery of cell viabilitya (siCtrl) (Fig. 4b).

We next sought to determine whether gene silencing of EGFR might also increase drug sensitivity to cisplatin. TCCSUP BC cells were transfected with EGFR siRNAs or control siRNAs for $48 \mathrm{~h}$. Immunoblotting confirmed that EGFR expression was significantly reduced in siEGFR-transfected cells (Fig. 5a). Interestingly, loss of EGFR made TCCSUP cells more sensitive to cisplatin-induced cell apoptosis, leading to reduced cell viability. TCCSUP cells were $\sim 2 \mathrm{x}$ more sensitive to 5 or $10 \mu \mathrm{M}$ cisplatin treatments (Fig. $5 \mathrm{~b}$ ). These results were further validated in T24 BC cells (Fig. 5c-d). These a

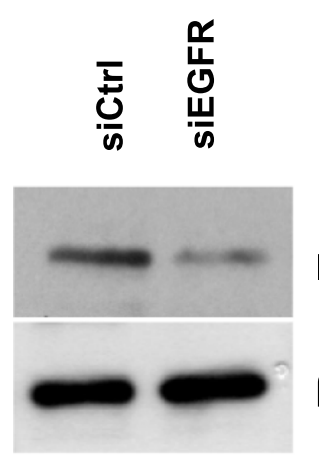

EGFR

$\beta$-actin

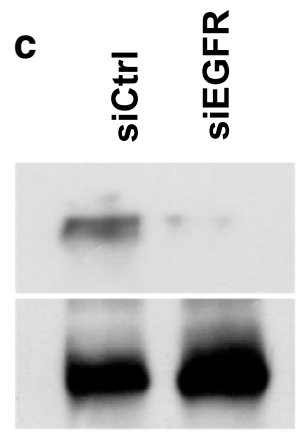

b

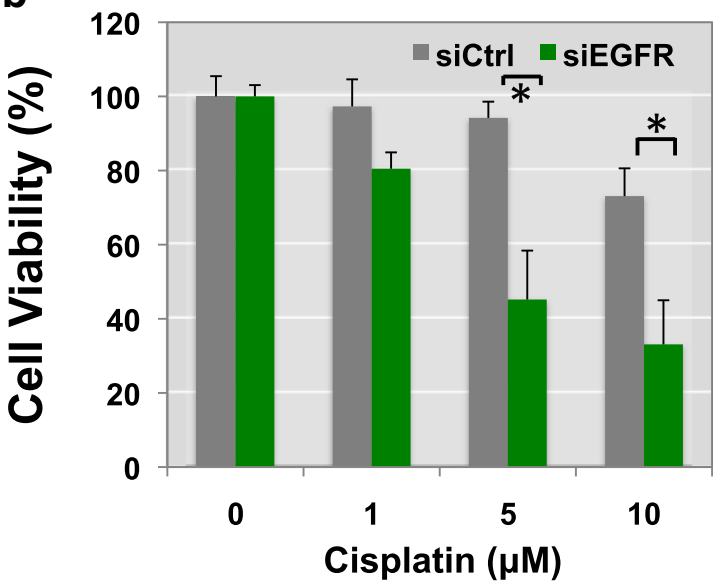

d

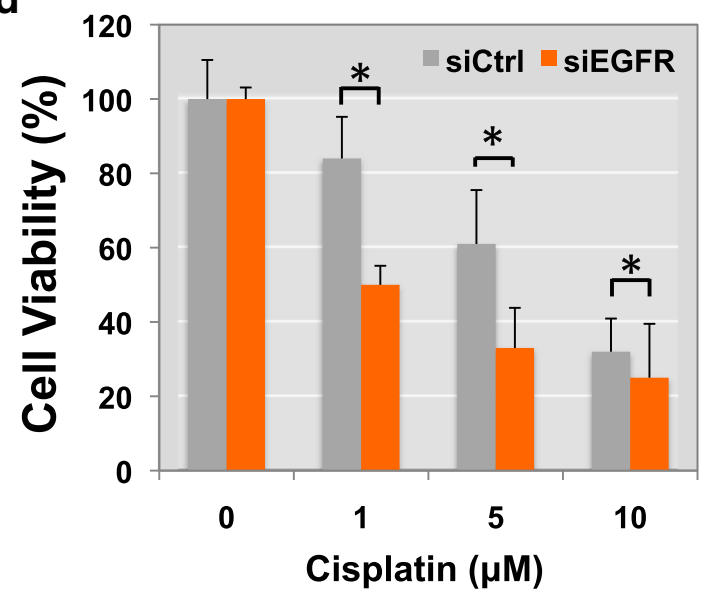

Fig. 5 Gene silencing of EGFR enhances drug sensitivity to cisplatin treatment. (a and b, TCCSUP; c and $\mathbf{d}$; T24) Transiently transfected TCCSUP (a) or T24 (c) cells with siRNA of EGFR were treated with cisplatin $(0,1,5$ and $10 \mu \mathrm{M})$. Cisplatin was added together with siNRA for $48 \mathrm{~h}$ and then re-treated with cisplatin. Cell viability was measured by MTS assay after 2 days. Overexpression of siEGFR, but not a control siRNA, in TCCSUP (c) or T24 (d) cells reduced cell proliferation (Student's t-test, ${ }^{*} p<0.05$ ) 
findings suggest that EGFR knockdown not only suppresses the recovery of $\mathrm{BC}$ cells from cisplatin-reduced cell viability but also enhances the sensitivity of $\mathrm{BC}$ cells to cisplatin's cytotoxicity.

\section{Discussion}

Systemic chemotherapy is currently being used as the first line of treatment in advanced stages of BC. However, it is still unclear which group of patients will benefit and which patients will be more sensitive to cisplatin-based therapy. Our findings suggest that EGFR overexpression is associated with disease recurrence following adjuvant chemotherapy for advanced $\mathrm{BC}[17,18]$. Determining EGFR expression status may help predict prognoses and assist in deciding which patients would best benefit from adjuvant chemotherapy. Our findings also suggest that patients with higher EGFR expression may have a worse prognosis than those with little to no EGFR expression. An evaluation of intratumoral molecular marker(s) could be used to identify BC patients more likely to respond to cisplatin-based chemotherapy.

These findings align with previous studies showing that approximately $50 \%$ of $\mathrm{BC}$ tumor tissues overexpress EGFR and that EGFR positivity indicates more invasive cells and poor differentiation [13, 14]. However, the mechanisms through which $\mathrm{BC}$ tumors acquire cisplatin resistance are still elusive. Our results suggest that EGFR silencing may enhance cisplatin's capability to shrink tumors. This observation highlights the potential of EGFR targeting strategies (e.g., kinase inhibitors or EGFR neutralizing antibodies such as gefitini, erlotinib, trastuzumab, cetuximab, matuzumutab, panitumumab et al.) to improve the effects of cisplatin-based chemotherapy. Recent reports have demonstrated that a subgroup of muscle-invasive bladder carcinomas with a basal-like phenotype are sensitive to EGFR kinase blockers, such as erlotinib [19, 20]. Rebouissou et al. identified a subgroup of aggressive MIBC, which shows a basal-like phenotype using their 40-gene expression classifier. In this BC subgroup, the EGFR pathway was highly activated, suggesting that anti-EGFR therapy could be used as a powerful therapeutic strategy [21, 22]. EGFR-targeted agents have only shown modest success due to acquired resistance in current ongoing clinical trials. Therefore, comprehensive clinical studies using EGFR-targeting in combination with other therapies would be more attractive.

\section{Conclusions}

Many questions regarding EGFR silencing strategies remain unanswered. For example, what signaling cascades are modulated by high EGFR expression? How can these be regulated pharmacologically? Will $\mathrm{BC}$ cells obtain resistance to cisplatin? Can cells become resistant to EGFR silencing? In this study, our experimental results present EGFR as a marker of recurrence in Egyptian BC patients. Further studies are needed to better understand the regulatory mechanisms of EGFR overexpression and its downstream signaling pathways in $\mathrm{BC}$, particularly in the context of squamous cell carcinoma (SCC) and transitional cell carcinoma (TCC). Our findings also suggest that elucidating some of these facets of EGFR and BC drug resistance might improve pharmacologic intervention.

\section{Abbreviations}

BC: Bladder cancer; EGFR: Epidermal growth factor receptor; MIBC: Muscleinvasive bladder cancer; siCtrl: Control cells; siRNAs: Small interfering RNAs

\section{Acknowledgements \\ None}

\section{Funding}

The authors acknowledge support from National Institutes of Health grants (1U01DK103260, 1R01DK100974, U24 DK097154, NIH NCATS UCLA CTSI

UL1TR000124), Department of Defense grants (W81XWH-15-1-0415), Centers for Disease Controls and Prevention (1U01DP006079), IMAGINE NO IC Research Grant, the Steven Spielberg Discovery Fund in Prostate Cancer Research Career Development Award, and the U.S.-Egypt Science and Technology Joint Fund (to J.K.). J.K. is former recipient of Interstitial Cystitis Association Pilot Grant, a Fishbein Family IC Research Grant, New York Academy of Medicine, and Boston Children's Hospital Faculty Development. The funders had no role in the experimental design, data collection, analysis, preparation of the manuscript, or decision to publish. In addition, this article is derived from the Subject Data funded in whole or part by National Academies of Sciences, Engineering, and Medicine (NAS) and The United States Agency for International Development (USAID). Any opinions, findings, conclusions, or recommendations expressed in this article are those of the authors alone, and do not necessarily reflect the views of USAID or NAS.

\section{Availability of data and materials}

All of data were presented in the main paper. The data that support the findings of this study are available on request from the corresponding author [J.K.]. The data are not publicly available due to information that could compromise research participant privacy.

\section{Authors' contributions}

JK and AMM conceived of the study, designed experiments, evaluated data and wrote the paper. AMM, ML, EC, VS, TP, MS, AM, MA, AA, and ME performed experiments. MS, AS, and AM provided expertise and supervised data interpretation. JK, AMM, and HA-E have contributed conceptually and intellectually and to the writing of the manuscript. All authors have read and approved the final manuscript.

\section{Ethics approval and consent to participate}

The biospecimens used in the present retrospective study were available from Mansoura University. The Ethics Committee of Mansoura Urology and Nephrology Center approved the protocol used for this study. The Institutional Review Board of Mansoura Urology and Nephrology Center approved analysis of all samples and database reviewed retrospectively (Mansoura UNC IRB \#RP-16-12-91). Consent from patients for use of the archived bladder specimens samples or their data was waived by the IRB because this study was retrospective study.

\section{Consent for publication}

Not applicable.

\section{Competing interests}

The authors declare that they have no competing interests.

\section{Publisher's Note}

Springer Nature remains neutral with regard to jurisdictional claims in published maps and institutional affiliations. 


\section{Author details}

'Urology and Nephrology Center, Mansoura University, Mansoura, Egypt. ${ }^{2}$ University of Texas Health Science Center, San Antonio, USA. ${ }^{3}$ University of California Los Angeles, Los Angeles, CA, USA. ${ }^{4}$ University of California, Berkerly, CA, USA. ${ }^{5}$ Departments of Surgery and Biomedical Sciences, Samuel Oschin Comprehensive Cancer Institute, Cedars Sinai Medical Center, 8700 Beverly Blvd, Los Angeles, CA 90048, USA.

Received: 3 January 2017 Accepted: 19 October 2018

Published online: 09 November 2018

\section{References}

1. Antoni S, Ferlay J, Soerjomataram I, Znaor A, Jemal A, Bray F. Bladder Cancer incidence and mortality: a global overview and recent trends. Eur Urol. 2017;71(1):96-108

2. Kamat AM, Hahn NM, Efstathiou JA, Lerner SP, Malmstrom PU, Choi W, Guo CC, Lotan Y, Kassouf W. Bladder cancer. Lancet. 2016;388(10061):2796-810.

3. Kaplan AL, Litwin MS, Chamie K. The future of bladder cancer care in the USA. Nature reviews Urology. 2014;11(1):59-62.

4. Mahdavifar N, Ghoncheh M, Pakzad R, Momenimovahed Z, Salehiniya H. Epidemiology, incidence and mortality of bladder cancer and their relationship with the development index in the world. Asian Pac J Cancer Prev. 2016;17(1):381-6.

5. Ibrahim AS, Khaled HM, Mikhail NN, Baraka H, Kamel H. Cancer incidence in Egypt: results of the national population-based cancer registry program. J Cancer Epidemiol. 2014;2014:437971.

6. Zaghloul MS, Nouh A, Moneer M, El-Baradie M, Nazmy M, Younis A. Timetrend in epidemiological and pathological features of schistosomaassociated bladder cancer. J Egyp Natl Cancer Inst. 2008;20(2):168-74.

7. Mostafa MH, Sheweita SA, O'Connor PJ. Relationship between schistosomiasis and bladder cancer. Clin Microbiol Rev. 1999;12(1):97-111.

8. Ghoneim MA, Abdel-Latif M, el-Mekresh M, Abol-Enein H, Mosbah A, Ashamallah A, el-Baz MA. Radical cystectomy for carcinoma of the bladder: 2,720 consecutive cases 5 years later. J Urol. 2008;180(1):121-7.

9. Grossman HB, Natale RB, Tangen CM, Speights VO, Vogelzang NJ, Trump DL, deVere White RW, Sarosdy MF, Wood DP Jr, Raghavan D, et al. Neoadjuvant chemotherapy plus cystectomy compared with cystectomy alone for locally advanced bladder cancer. N Engl J Med. 2003;349(9):859-66.

10. Mansour AM, Soloway MS, Eldefrawy A, Singal R, Joshi S, Manoharan M. Prognostic significance of cystoscopy findings following neoadjuvant chemotherapy for muscle-invasive bladder cancer. Can J Urol. 2015:22(2):7690-7.

11. Rosenblatt R, Sherif A, Rintala E, Wahlqvist R, Ullen A, Nilsson S, Malmstrom PU, Nordic Urothelial Cancer G. Pathologic downstaging is a surrogate marker for efficacy and increased survival following neoadjuvant chemotherapy and radical cystectomy for muscle-invasive urothelial bladder cancer. Eur Urol. 2012;61(6):1229-38.

12. Black PC, Dinney CP. Growth factors and receptors as prognostic markers in urothelial carcinoma. Curr Urol Rep. 2008;9(1):55-61.

13. Abbosh PH, McConkey DJ, Plimack ER. Targeting signaling transduction pathways in bladder Cancer. Curr Oncol Rep. 2015;17(12):58

14. van Kessel KE, Zuiverloon TC, Alberts AR, Boormans JL, Zwarthoff EC. Targeted therapies in bladder cancer: an overview of in vivo research. Nature Rev Urol. 2015:12(12):681-94.

15. Lee HH, Wang YN, Hung MC. Non-canonical signaling mode of the epidermal growth factor receptor family. Am J Cancer Res. 2015;5(10):2944-58.

16. Tan X, Lambert PF, Rapraeger AC, Anderson RA. Stress-induced EGFR trafficking: mechanisms, functions, and therapeutic implications. Trends Cell Biol. 2016;26(5):352-66.

17. Kim WT, Kim J, Yan C, Jeong P, Choi SY, Lee OJ, Chae YB, Yun SJ, Lee SC, Kim WJ. S100A9 and EGFR gene signatures predict disease progression in muscle invasive bladder cancer patients after chemotherapy. Ann Oncol. 2014:25(5):974-9.

18. Symanowski JT, Kim ES. Gene expression and prognosis in bladder cancer-real progress? Editorial on 'S100A9 and EGFR gene signatures predict disease progression in muscle invasive bladder cancer patients after chemotherapy. Ann Oncol. 2014;25(5):919-20.

19. Choi W, Czerniak B, Ochoa A, Su X, Siefker-Radtke A, Dinney C, McConkey DJ. Intrinsic basal and luminal subtypes of muscle-invasive bladder cancer. Nature Rev Urol. 2014;11(7):400-10
20. Shah JB, McConkey DJ, Dinney CP. New strategies in muscle-invasive bladder cancer: on the road to personalized medicine. Clin Cancer Res. 2011;17(9):2608-12.

21. Bladder cancers respond to EGFR inhibitors. Cancer discovery. 2014, 4(9):980-981.

22. Rebouissou S, Bernard-Pierrot I, de Reynies A, Lepage ML, Krucker C Chapeaublanc E, Herault A, Kamoun A, Caillault A, Letouze E, et al. EGFR as a potential therapeutic target for a subset of muscle-invasive bladder cancers presenting a basal-like phenotype. Sci Transl Med. 2014;6(244):244ra291.
Ready to submit your research? Choose BMC and benefit from:

- fast, convenient online submission

- thorough peer review by experienced researchers in your field

- rapid publication on acceptance

- support for research data, including large and complex data types

- gold Open Access which fosters wider collaboration and increased citations

- maximum visibility for your research: over $100 \mathrm{M}$ website views per year

At BMC, research is always in progress.

Learn more biomedcentral.com/submissions 